\title{
Inhibition of hepatocellular carcinoma cell growth by an anti- insulin-like growth factor-I receptor monoclonal antibody
}

\author{
LU YUE $^{1 *}$, YING WANG $^{2 *}$, HUAMAO WANG $^{3}$, HUIPING GAO $^{3}$, JUN LIANG $^{1}$, AIHUA SUI $^{4}$, JINYU XIANG $^{1}$, \\ FANG ZHOU ${ }^{1}$, CONGCONG XU $^{1}$, WENWEN ZHAO ${ }^{1}$, WANHUA LIANG ${ }^{1}$ and RUYONG YAO ${ }^{4}$ \\ ${ }^{1}$ Department of Oncology, Affiliated Hospital of Qingdao University, Medical College, Qingdao; \\ ${ }^{2}$ Shanghai Xuhui Central Hospital, Shanghai; ${ }^{3}$ State Key Laboratory of Oncogenes and Related Genes, \\ Renji Hospital, Medical School of Shanghai JiaoTong University, Shanghai; ${ }^{4}$ Central Laboratory, \\ Affiliated Hospital of Qingdao University, Medical College, Qingdao, P.R. China
}

Received April 12, 2012; Accepted July 18, 2012

DOI: 10.3892/or.2012.1960

\begin{abstract}
Hepatocellular carcinoma (HCC) overexpresses insulin-like growth factor-I receptor (IGF-IR), as compared with normal hepatocytes. Since IGF-1R-mediated signaling promotes survival, oncogenic transformation and tumor growth and spread, it represents a potential target for treating HCC. Here, we have generated a murine anti-IGF-1R antibody, $4 \mathrm{~F} 2$, that recognizes the IGF-IR $\alpha$ subunit and blocks in vitro IGF-I and IGF-II-induced cell proliferation of SMMC-7721 and Bel-7402 HCC cell lines. 4F2 can inhibit IGF-IR autophosphorylation, IRS-1 phosphorylation and the activation of the major downstream signaling molecules AKT and mitogenactivated protein kinase. Additionally, we observed a moderate increase in apoptosis as demonstrated by detection of changes in the expression of the pro-apoptotic and anti-apoptotic proteins Bax and Bcl-2 after 4F2 treatment. Combined treatment with 4F2 and doxorubicin was more effective in reducing cell proliferation and promoting apoptosis than either agent alone. These data support that therapeutic anti-IGF-IR antibodies are potential new agents for treating HCC.
\end{abstract}

\section{Introduction}

The insulin-like growth factor receptor-I (IGF-IR) is a membranebound tyrosine kinase receptor that plays an important role in

Correspondence to: Dr Ruyong Yao, Central Laboratory, Affiliated Hospital of Qingdao University, Medical College, 16 Jiangsu Road, Qingdao 266003, P.R. China

E-mail: yry0303@163.com

\section{${ }^{*}$ Contributed equally}

Abbreviations: HCC, hepatocellular carcinoma; IGF-IR, insulinlike growth factor-I receptor; MAPK, mitogen-activated protein kinase; IRS-1, insulin receptor substrate-1; ERK, extracellular signal-regulated kinase; FITC, fluorescein isothiocyanate

Key words: IGF-IR, 4F2, HCC, doxorubicin, apoptosis tumor cell proliferation, differentiation, apoptosis and metastasis $(1,2)$. IGF-IR can bind with both IGF-I and IGF-II and is overexpressed in some cancers (3-8). The expression of IGF-IR was constitutively low in normal hepatocytes, but highly expressed in HCC and HCC cell lines (9). Epidemiologic data have shown that elevated plasma IGF-I level is linked with prostate, breast, lung and colon cancer risk $(10,11)$. IGF-II is frequently overexpressed in liver cancer (12-17). The level of IGF-II is highly expressed in many human malignancies, such as breast cancer, pediatric tumors, colon cancer and hepatocellular carcinoma (HCC) $(18,19)$. Binding of IGF-II with IGF-IR has been associated with increased tumor cell mitosis and anti-apoptosis as well as enhanced angiogenesis (20). Therefore, IGF-IR is an attractive antitumor target for HCC.

Mitogen-activated protein kinase (MAPK) and phosphatidylinositol 3/-kinase/AKT are the principle pathways for transduction of the IGF signal $(21,22)$. After ligand-dependent receptor autophosphorylation, IGF-IR phosphorylates a series of adaptor proteins, such as insulin receptor substrate-1 (IRS-1), to activate intracellular signaling pathways. The MAPK pathway plays an important role in the mitogenic signal elicited after IGF stimulation but may also function in cell survival in cells overexpressing the IGF-IR $(23,24)$. After IGF stimulation the phosphatidylinositol 3/-kinase elicits survival processes including the activation of the Akt and, as a result, has been shown to protect cells from damage-induced apoptosis (25).

The development of specific small molecule inhibitors of IGF-IR tyrosine kinase activity was challenging because of the high degree of homology to insulin receptor. Recently, many neutralizing antibodies specific for IGF-IR have been developed such as $\alpha$-IR3 (26), scFv-FC (27), CP-751,871 (28) and IMC-A12 (29). Although the antitumor effects of these antibodies were tested for several cell types in preclinical studies, no comprehensive research regarding the antitumorigenic impact on HCC cells have been reported to date. Here, we generated a murine anti-IGF-IR antibody to test our hypothesis both in vitro and in vivo by treating HCC tumor cells with the 4F2 antibody alone and in combination with the cytotoxic chemotherapeutic drugs. The mechanism underlying the antitumor effect of 4F2 was also elucidated. 


\section{Materials and methods}

Cell lines and culture. The human HCC cell lines SMMC-7721, 7402 and breast cancer cell lines MCF-7, MDA-MB-468 were cultured in DMEM medium containing 10\% fetal bovine serum, NIH3T3 cells overexpressing IGF-1R, NIH3T3/IGF-1R were constructed by our laboratory and grown in DMEM supplemented with $10 \%$ fetal bovine serum.

Reagents. Human recombinant IGF-I and IGF-II were purchased from Calbiochem. Annexin V-FITC apoptosis detection kit I was from BD Biosciences. Specific antibodies against the following antigens were used: IGF-IR $\beta$ (C20), insulin receptor (C19), IGF-IR $\alpha$ (3B7), phospho-Y1158/1162/1163 IGF-IR, ERK2, AKT, phospho-S473 AKT, phospho-p42/ p44 extracellular signal-regulated kinase (ERK), bcl-2, p27, CycineD1 (Santa Cruz Biotechnology); IRS-1, phospho-Y896, IRS-1, Bax, Bad (Epitomics); 4G10 (Up-state Biotechnology). Anti-mouse and anti-rabbit horseradish peroxidase conjugates were from Amersham. Cell Counting Kit-8 was from Dojindo Laboratories.

Generation of anti-IGF-IR antibodies. BALB/c mice were immunized i.p. with human IGF-IR overexpressing 3T3-IGF-1R cells $\left(5 \times 10^{5}\right.$ cells, suspended in $0.2 \mathrm{ml}$ of PBS) with Freund's adjuvant. Some of the animals were boosted with $10^{6}-10^{7}$ cells several times before fusion. The splenocytes from immunized mice were isolated and used to generate hybridoma according to standard protocols (30). The hybridoma supernatants were screened by ELISA for specific binding to the 3T3-IGF-IR cells used for immunization and for the absence of binding to 3T3 cells. Immulon-2HB plates (Dynatech) precoated with $100 \mu \mathrm{l}$ of phytohemagglutinin lectin $(20 \mu \mathrm{g} / \mathrm{ml}$; Sigma) were charged with trypsin/EDTA treated cells $\left(1-3 \times 10^{6}\right.$ cells/100 $\left.\mu \mathrm{l}\right)$, centrifuged, then kept at ambient temperature for $10 \mathrm{~min}$ and finally dried overnight at $37^{\circ} \mathrm{C}$. The wells were blocked with $5 \mathrm{mg} / \mathrm{ml} \mathrm{BSA}$ in PBS (blocking solution) for $1 \mathrm{~h}$ at $37^{\circ} \mathrm{C}$, washed gently with PBS, and then incubated with supernatants from hybridoma clones (diluted in blocking solution) for $1 \mathrm{~h}$. The wells were washed with PBS, incubated with goat anti-mouse-IgG-Fcantibody-HRP conjugate $(0.8 \mu \mathrm{g} / \mathrm{ml}$; in blocking solution) for $1 \mathrm{~h}$, washed, and the binding was detected using ABTS $/ \mathrm{H}_{2} \mathrm{O}_{2}$ substrate $\left[0.5 \mathrm{mg} / \mathrm{ml}\right.$ ABTS, $0.03 \% \mathrm{H}_{2} \mathrm{O}_{2}, 0.1 \mathrm{M}$ citrate buffer (pH 4.2); $405 \mathrm{~nm}$ ]. A hybridoma supernatant was identified, which showed strong binding to 3T3-IGF-IR cells and not to 3T3 cells. Using protein A affinity chromatography, a murine IgG2a antibody was isolated from the hybridoma supernatant and designated $4 \mathrm{~F} 2$.

$R T$-PCR. Total RNA was extracted from cultured cell lines with RNA Clean following the recommendation of the manufacturer (Hybaid, London, UK). To eliminate any possible contamination with genomic DNA, RNAs were treated with 1 unit DNase per mg RNA for $15 \mathrm{~min}$ at room temperature and were then reverse transcribed into cDNA using oligo(dt) primers and the SuperScript Preamplification-Kit following the manufacturer's instructions (Gibco). PCR reactions were carried out in a total volume of $50 \mu \mathrm{l}$ containing $400 \mathrm{nM}$ of each primer, $200 \mathrm{mM}$ of each dNTP (Pharmacia, Uppsala, Sweden), $50 \mathrm{mM} \mathrm{KCl}, 1.5 \mathrm{mM} \mathrm{MgCl} 2,10 \mathrm{mM}$ Tris and 1 unit
Taq-polymerase (Pharmacia). The primers for IGF-IR were 5'-GGGAATGGAGTGCTGTATG-3' (forward) and 5'-CACA GAAGCTTCGTTGAGAA-3' (reverse). Amplification of human $\beta$-actin served as an internal control. The primers used were 5'-GGACCTGACTGACTACCTC-3' (forward) and 5'-TCATA CTCCTGCTTGCTG-3' (reverse).

Immunocytochemistry labeling and microscopy. The cellular localization of proteins of interest was accomplished by indirect immunocytochemistry. Briefly, SMMC-7721, Bel-7402 and 3T3-IGF-1R cells were plated on sterile glass cover slips in 6-well plates and allowed to attach overnight. Cells were then rinsed twice in PBS, fixed in $4 \%$ phosphate-buffered paraformaldehyde for $15 \mathrm{~min}$, and permeabilized in acetone at $-20^{\circ} \mathrm{C}$ for $4 \mathrm{~min}$. Following permeabilization, cells were blocked in 5\% normal goat serum-PBS for $30 \mathrm{~min}$, incubated with a primary antibody against IGF-IR for $1 \mathrm{~h}$ at room temperature, washed thrice in PBS, and then incubated with goat anti-mouse secondary antibodies. Cells were then incubated $1 \mathrm{~h}$ with peroxidase-anti-peroxidase mix and rinse with buffer as before. Then cells were incubated in fresh DAB solution $\left(10 \mathrm{mg}\right.$ DAB $+20 \mu 138 \% \mathrm{H}_{2} \mathrm{O}_{2}$ in $20 \mathrm{ml} 0.1 \mathrm{M}$ Tris pH 7.2; $200 \mu \mathrm{l} 1 \mathrm{M}$ imidazole), The reaction was stopped by washing in water when a uniform brown color first became visible on the cells. Microscopic analyses were done using a Leica 4000B microscope in accordance with established methods.

Immunoprecipitation and western blot analysis. Cells were plated into 6-well culture dishes and grown to $70-80 \%$ confluence. Monolayers were washed twice in PBS and cultured overnight in serum-free medium. Antibody was then added in fresh serum-free medium and incubated at $37^{\circ} \mathrm{C}$ for $2 \mathrm{~h}$. Cells were incubated with ligand for $15 \mathrm{~min}$ and then placed on ice and washed with ice-cold PBS. For immunoprecipitation of pure IRs, IGF-IR-depleted supernatant from an IGF-IR immunoprecipitate was immunoprecipitated with anti-insulin antibody C19 or 4F2. To isolate pure IGF-IRs, IR-depleted supernatant from an IR immunoprecipitate was immunoprecipitated with anti-IGF-IR antibody C-20 or 4F2. Immunoprecipitates bound to the protein A-agarose beads were stripped into denaturing gel sample buffer. Lysates or immunoprecipitates were processed for denaturing gel electrophoresis and run on a 10\% SDS-PAGE, and blotted to nitrocellulose membrane by western blotting.

Cell proliferation/survival assays. The effect of $4 \mathrm{~F} 2$ treatment on the growth of human HCC cell lines SMMC-7721, Bel-7402 upon stimulation by IGF-I, IGF-II or serum was measured using the CCK- 8 assay after 3 days. Typically, 1500-3000 cells/ well were plated in a 96-well plate in regular growth medium with serum, which was replaced with serum-free medium the next day. After 1 day of incubation in serum-free medium, the cells were washed gently with serum-free medium and then incubated with 4F2 antibody and doxorubicin alone or combination in serum-free medium for $2 \mathrm{~h}$, which was followed by the addition of IGF-II solution (or IGF-I solution or serum) to obtain a final concentration of $5-50 \mu \mathrm{g} / \mathrm{ml} 4 \mathrm{~F} 2$ antibody and $20 \mathrm{ng} / \mathrm{ml}$ IGF-II (or $20 \mathrm{ng} / \mathrm{ml}$ IGF-I or $2 \%$ serum). The cells were then allowed to grow for 3 days. Of the CCK-8 solution $10 \mu \mathrm{l}$ was added to cells cultured for the designated time. The plates were incubated for $1-4 \mathrm{~h}$ in the incubator. The resulting 
A

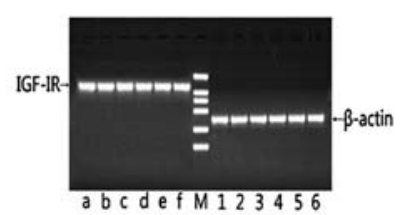

C

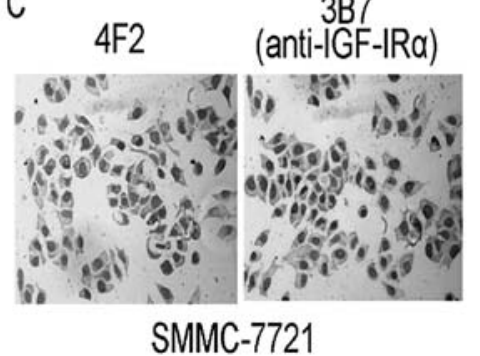

B

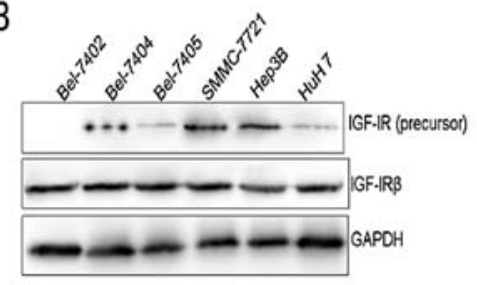

4F2

3B7

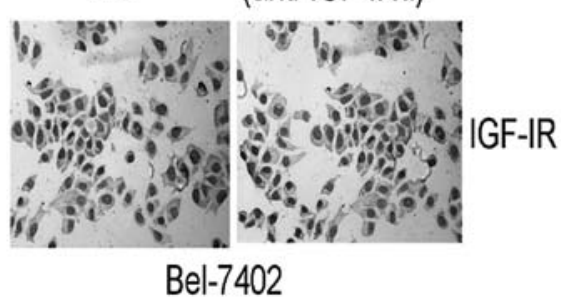

Figure 1. Expression of IGF-IR in hepatocellular carcinoma. (A) mRNA expression of IGF-IR (amplicon size, 541 bp) in Bel-7402 (lane a), Bel-7404 (lane b), Bel-7405 (lane c), SMMC-7721 (lane d), HuH7 (lane e) and Hep3B (lane f) cells. The expression of the housekeeping gene $\beta$-actin (amplicon size, 260 bp) in Bel-7402 (lane 1), Bel-7404 (lane 2), Bel-7405 (lane 3), SMMC-7721 (lane 4), HuH7 (lane 5) and Hep3B (lane 6) cells was analyzed for standardization. M, DL2000 DNA ladder. (B) Expression of IGF-IR and IGF-IR-precursor protein was evaluated by western blot analysis. (C) The localization of IGF-IR protein in SMMC-7721 and Bel-7402 cells were investigated by immunocytochemistry detection with 4F2 or anti-IGF-IR (3B7) antibody.

color was assayed at $450 \mathrm{~nm}$ using a microplate absorbance reader (Tecan, Safire II, Switzerland).

Inhibition of IGF-IR-mediated cell signaling by 4F2. The potential of 4F2 to inhibit the IGF-I-stimulated autophosphorylation of IGF-IR and the phosphorylation of downstream effectors, IRS-1, Akt and ERK, was studied in SMMC-7721 cells. Antibodies were added to cells for $2 \mathrm{~h}$. Cells were then stimulated with $20 \mathrm{ng} / \mathrm{ml} \mathrm{IGF-I} \mathrm{or} \mathrm{IGF-II} \mathrm{for} 15 \mathrm{~min}$ at $37^{\circ} \mathrm{C}$, washed twice with cold PBS containing $0.1 \mathrm{mmol} / 1$ sodium vanadate and lysed in lysis buffer [50 mmol/1 HEPES (pH 7.4), $150 \mathrm{mmol} / 1 \mathrm{NaCl}, 10 \%$ glycerol, $1 \%$ Triton $\mathrm{X}-100,1.5 \mathrm{mmol} / \mathrm{l}$ $\mathrm{MgCl}_{2}$, protease inhibitors, $2 \mathrm{mmol} / 1$ sodium vanadate]. Lysates were incubated on ice for $30 \mathrm{~min}$ and then centrifuged at $13000 \mathrm{rpm}$ for $10 \mathrm{~min}$ at $4^{\circ} \mathrm{C}$. Protein concentrations of the lysates were measured with BCA kit (Pierce). Lysates were then subjected to immunoprecipitation and western blot analysis.

Receptor degradation analysis. SMMC-7721 cells were plated in regular culture medium followed by overnight incubation in serum-free medium. IGF-I, IGF-II $(20 \mathrm{ng} / \mathrm{ml})$ or $4 \mathrm{~F} 2$ was then added and cells were incubated at $37^{\circ} \mathrm{C}$ for up to $24 \mathrm{~h}$. Cells were washed in ice-cold PBS, lysed in immunoprecipitation assay buffer, and quantitated by BCA kit (Pierce). Equal amount of cell lysates was separated on $10 \%$ SDS-PAGE, transferred to nitrocellulose filters, probed with an anti-IGF-IR rabbit polyclonal $\mathrm{IgG}$ and revealed with an anti-rabbit IgG coupled to the HRP and visualized by ECL.

Apoptosis assays. SMMC-7721 cells were treated with 4F2 or doxorubicin in the presence of IGF-II (or serum) for $24 \mathrm{~h}$. Apoptotic and necrotic index were assessed by flow cytometry, using fluorescein isothiocyanate (FITC) labeled Annexin V, and simultaneously with PI stain. Cells were washed twice with ice-cold PBS and incubated for $30 \mathrm{~min}$ in a binding buffer ( $1 \mu \mathrm{g} / \mathrm{ml}$ PI and $1 \mu \mathrm{g} / \mathrm{ml}$ FITC labeled Annexin V), respectively. FACS analysis for Annexin V and PI staining was performed by flow cytometry. All experiments were performed in triplicate.

Statistical analysis. Student's t-test and One-way ANOVA analysis were performed for continuous variables. The $\chi^{2}$ test or Fisher's exact test were used for categorical variables. The error bars represent the standard error of the mean. Statistical significance for all the tests, assessed by calculating P-value, was $<0.05$ from two-sided tests. The statistical analyses were performed using SAS 9.0 software (SAS Inc., Cary, NC, USA).

\section{Results}

Identification of an inhibitory anti-IGF-IR monoclonal antibody through a rapid biological screen. To generate monoclonal antibodies, BALB/c mice were immunized and subsequently boosted with 3T3-IGF-IR cells that overexpress human IGF-IR. The generated hybridoma supernatants were screened by cell-based ELISA methods for specificity of binding and biological activity. The hybridoma clones that bound to the 3T3-IGF-IR cells but not to the NIH-3T3 cells were selected. The selected antibody clones were further screened by their growth, inhibiting activity on HCC cells using CCK-8 assay (data not shown). As the most effective inhibitory antibody clone, 4F2 was picked out for further study.

Expression of IGF-1R in hepatocellular carcinoma. mRNA expression of the insulin-like growth factor receptor 1 (IGF-1R) was investigated in the human hepatoblastoma and hepatocelluar carcinoma cell lines. Robust expression of mRNAs specific for IGF-1R was detected in all cell lines (Fig. 1A). To evaluate the protein expression of IGF-1R, western blot analysis was performed. Both the IGF-1R precursor and 

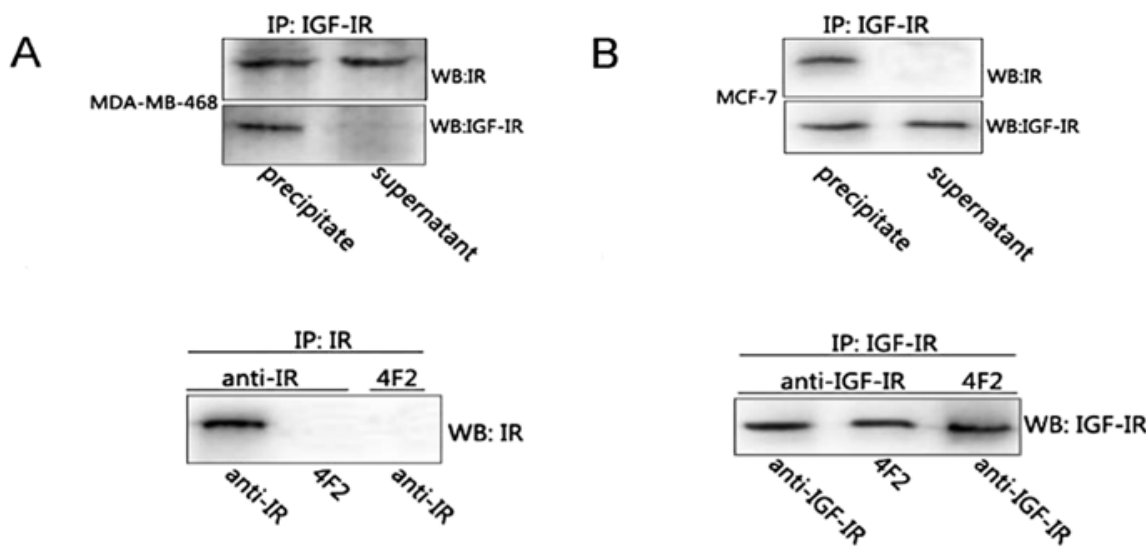

C

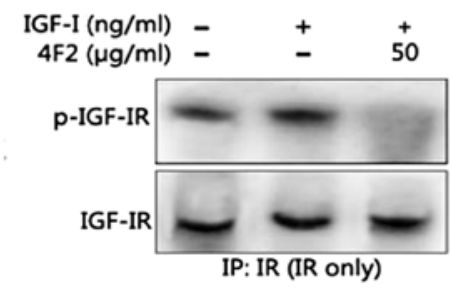

MCF-7

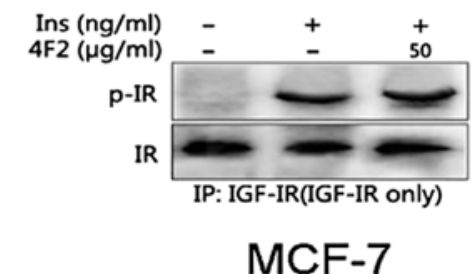

Figure 2. The specificity identification of 4F2 by western blot analysis. MDA-MB-468 (A) or MCF-7 (B) cell lysate was first cleared of IGF-IRs or IRs and hybrids by immunoprecipitation with an IGF-IR or IR-specific antibody and then immunoprecipitated with an IR or IGF-IR specific antibody and 4F2, analyzed by western blotting with an IR or IGF-IR-specific antibody and 4F2, respectively. Immunoprecipitation and western blot analysis of insulin-like growth factor I receptor (IGF-IR), phosphorylation (C) or insulin receptor (IR) phosphorylation (D) in breast cancer cells after stimulation with IGF-I or insulin in the presence or absence of blocking antibodies. To isolate classical IGF-IR or IR from cells, cell lysate was first cleared of IRs or IGF-IRs and hybrids by immunoprecipitation with an IR or IGF-IR-specific antibody and then immunoprecipitated with an IGF-IR or IR-specific antibody. Phosphorylated receptor was detected with a phosphotyrosine-specific antibody (4G10).

the $\beta$-chain of the mature form of IGF-1R were detected in HCC cells (Fig. 1B). Immunocytochemistry results show that most IGF-IR located in the cell membrane and cytoplasm of SMMC-7721 and Bel-7402 cells.

Specificity identification of $4 F 2$. Since IGF-IR shares considerable homology with the IR (34), it is necessary to demonstrate the selectivity of 4F2 for the IGF-IR. We performed successive immunoprecipitation of IGF-IR and IR in MDA-MB-468 and MCF-7 cell lines, which possess a greater IGF-IR:IR and IR:IGF-IR ratio, respectively (31), to obtain purified classical IGF-IR and IR homodimers. Immunoprecipitation and immunoblot analysis showed that $4 \mathrm{~F} 2$ bound selectively to IGF-IR but not to IR (Fig. 2A and B). To demonstrate selective blocking effect on IGF-IR signaling but not IR signaling by 4F2, we performed successive immunoprecipitation after cells were treated with IGF-I and insulin stimulation. Immunoblot analysis showed that 4F2 completely inhibited the phosphorylation of IGF-IR but not that of IR (Fig. 2C and D).

$4 F 2$ inhibits the proliferation of $\mathrm{HCC}$ cells. To characterize the in vitro antiproliferative effect of 4F2, HCC cell lines were grown in serum-free medium with exogenously added IGF-I/ IGF-II in the presence or absence of 4F2, typically for 3 days, and the cell viability was then measured by CCK-8 assay. We found a dose-dependent reduction in the number of viable cells (Fig. 3). In similar experiments based on the CCK-8 assay after 3 days of growth, 4F2 treatment caused dose-dependent inhi- bition of the serum (2\%)-stimulated proliferation and survival of SMMC-7721 and Bel-7402 cells, implicating the essential role of IGF-I as a growth factor present in serum (Fig. 3).

Antineoplastic potency of $4 F 2$ in combination with the doxorubicin. Several studies have reported that combinations of doxorubicin and small molecular inhibitor of IGF-IR resulted in additive growth inhibitory effects on HCC cells (36). We studied possible (over-) additive antineoplastic effects of 4F2 plus doxorubicin in $\mathrm{HCC}$ cells. Cells were treated with 4F2 $(20 \mu \mathrm{g} / \mathrm{ml})$ alone or in combination with rising concentrations of the doxorubicin (50-250 $\mathrm{nM}$ ) for $72 \mathrm{~h}$. Upon treatment with doxorubicin alone, a dose-dependent growth inhibition was observed after $72 \mathrm{~h}$ in SMMC-7721 (Fig. 4A) and Bel-7402 cells (Fig. 4B), $250 \mathrm{nM}$ of doxorubicin caused a 51 and $34 \%$ inhibition in SMMC-7721 and Bel-7402 cells, respectively $(\mathrm{P}<0.01)$. The antineoplastic effects of doxorubicin increased when the doxorubicin was combined, approximately 69 and $58 \%$ inhibition was observed when $20 \mu \mathrm{g} / \mathrm{ml} 4 \mathrm{~F} 2$ was combined with $250 \mathrm{nM}$ doxorubicin in SMMC-7721 and Bel-7402 cells $(\mathrm{P}<0.01)$. Combinatorial treatment with $4 \mathrm{~F} 2$ and doxorubicin resulted in significantly higher inhibitory effects on SMMC-7721 and Bel-7402 cells than treatment with $4 \mathrm{~F} 2(\mathrm{P}<0.001)$ or doxorubicin $(\mathrm{P}<0.05)$ alone.

The anti-IGF-IR therapeutic antibody $4 F 2$ blocks IGF-induced $I G F-I R$ signaling and downregulates the expression of IGF-IR in HCC cells. The effect of 4F2 on the IGF-I-stimulated or 

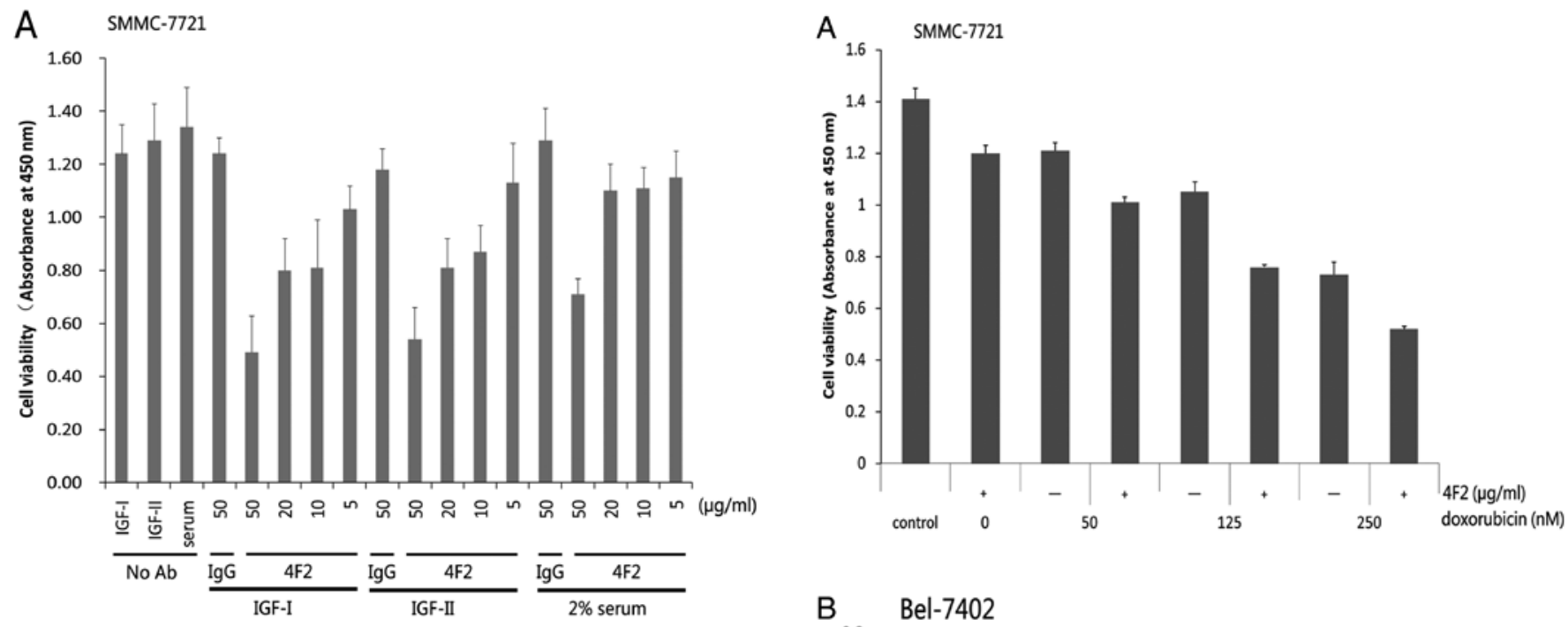

B
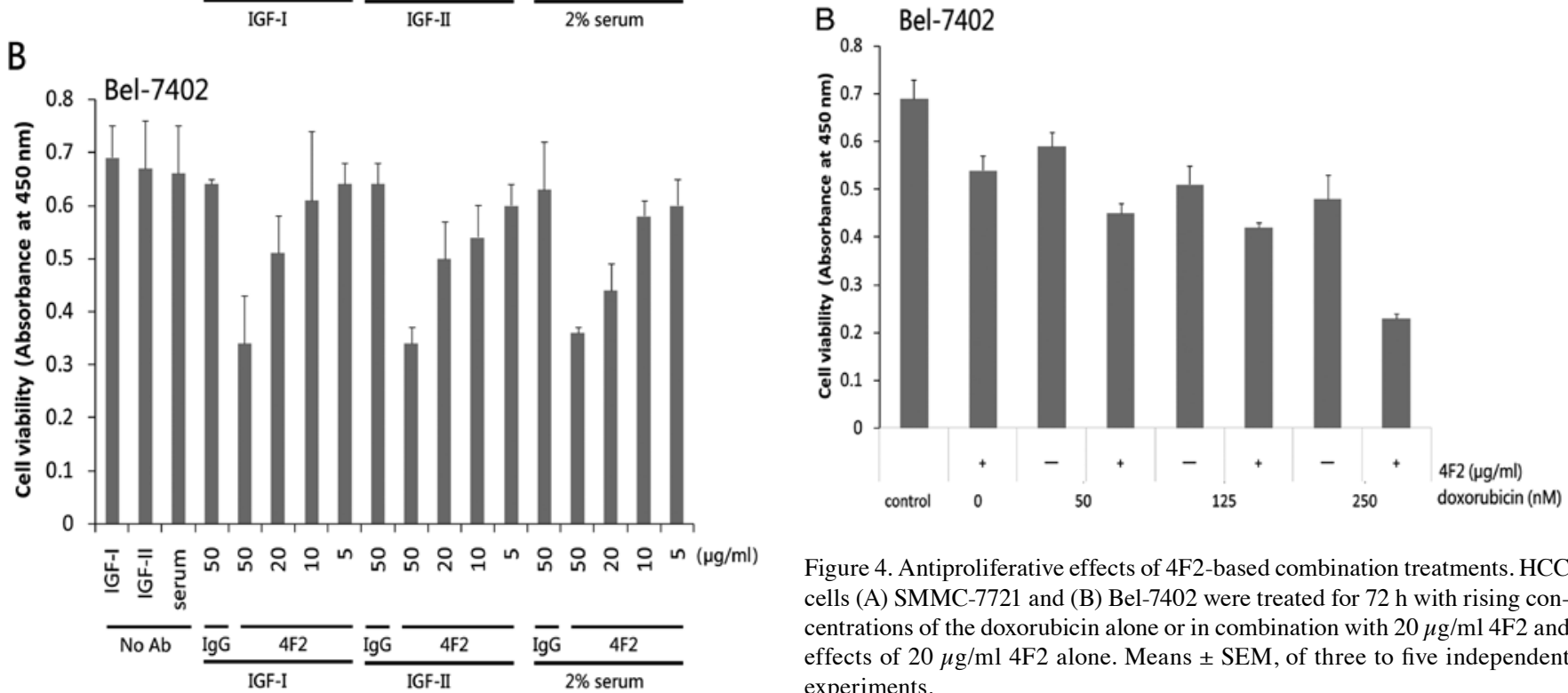

Figure 4. Antiproliferative effects of $4 \mathrm{~F} 2$-based combination treatments. HCC cells (A) SMMC-7721 and (B) Bel-7402 were treated for $72 \mathrm{~h}$ with rising concentrations of the doxorubicin alone or in combination with $20 \mu \mathrm{g} / \mathrm{ml} 4 \mathrm{~F} 2$ and effects of $20 \mu \mathrm{g} / \mathrm{ml} 4 \mathrm{~F} 2$ alone. Means \pm SEM, of three to five independent experiments.

Figure 3. Potent inhibition of proliferation and survival of cancer cells by $4 \mathrm{~F} 2$. Cancer cells were treated with $4 \mathrm{~F} 2$ and control antibody in the presence of IGF-I, IGF-II or serum, and the proliferation of cells was monitored using CCK-8 assay (after 3 days). (A) and (B) inhibition of IGF-I, IGF-II or serumstimulated proliferation of HCC cells SMMC-7721 and Bel-7402 by different concentration of 4F2 and control antibody.

IGF-II-stimulated activation of IGF-IR and the downstream signaling were then measured. Serum-starved SMMC-7721 cells were treated for $2 \mathrm{~h}$ with various concentrations of $4 \mathrm{~F} 2$ and then stimulated with IGF-I or IGF-II in serum-free medium for $15 \mathrm{~min}$. The cells were then lysed and the lysates were analyzed for the phosphorylation levels of effector proteins in the IGF-IR-signaling pathway, including IGF-IR, IRS-1, Akt and MAPK. At a concentration of $50 \mu \mathrm{g} / \mathrm{ml}, 4 \mathrm{~F} 2$ completely inhibited both IGF-I-induced and IGF-II-induced phosphorylation of IGF-IR (Fig. 5A). In addition, at concentrations of 20 and $50 \mu \mathrm{g} / \mathrm{ml}, 4 \mathrm{~F} 2$ inhibited IGF-I-induced and IGF-II-induced phosphorylation of IRS-I, Akt and MAPK (Fig. 5A). To evaluate the potential downregulation of IGF-IR by $4 \mathrm{~F} 2$ treatment, the level of IGF-IR $\beta$ chain in 4F2-treated SMMC-7721 cells was assessed by western blotting. No detectable decrease in the amount of IGF-IR $\beta$ chain was seen during the first $4 \mathrm{~h}$ of treatment with 4F2 in Bel-7402 and SMMC-7721 cells, but

a modest downregulation of the receptor was observed after 48-h treatment (Fig. 5B). In contrast, no downregulation of IGF-IR $\beta$ was observed upon treatment with the ligand IGF-I and IGF-II.

$4 F 2$ enhances the induction of apoptosis by doxorubicin. The CCK- 8 assays above show that 4F 2 combined with doxorubicin additively inhibits HCC cells growth but does not characterize the mechanism of cell death. To examine whether 4F2 enhanced cytotoxicity of doxorubicin to cancer cells was mediated through increased apoptosis, Annexin V/PI staining was used to examine the apoptosis in SMMC-7721 cells. From the statistical analysis of cytometry data, we found that doxorubicin combined with $20 \mu \mathrm{g} / \mathrm{ml}$ 4F2 induced more apoptotic cells $(30.4 \pm 1.56 \%, \mathrm{P}<0.01)$ than doxorubicin alone $(17.1 \pm 1.25 \%$, Fig. 6). In order to determine whether the increased cytotoxicity reflected induction of apoptosis, Annexin $\mathrm{V}$ binding and propidium iodide staining were carried out using the Annexin V-FITC Apoptosis Detection Kit 1 (BD Pharmingen) and flow cytometry. As show in Fig. 6, combination of $20 \mu \mathrm{g} /$ $\mathrm{ml} 4 \mathrm{~F} 2$ and doxorubicin resulted in a nearly 2-fold increase in apoptosis relative to control. The combination seemed to result 

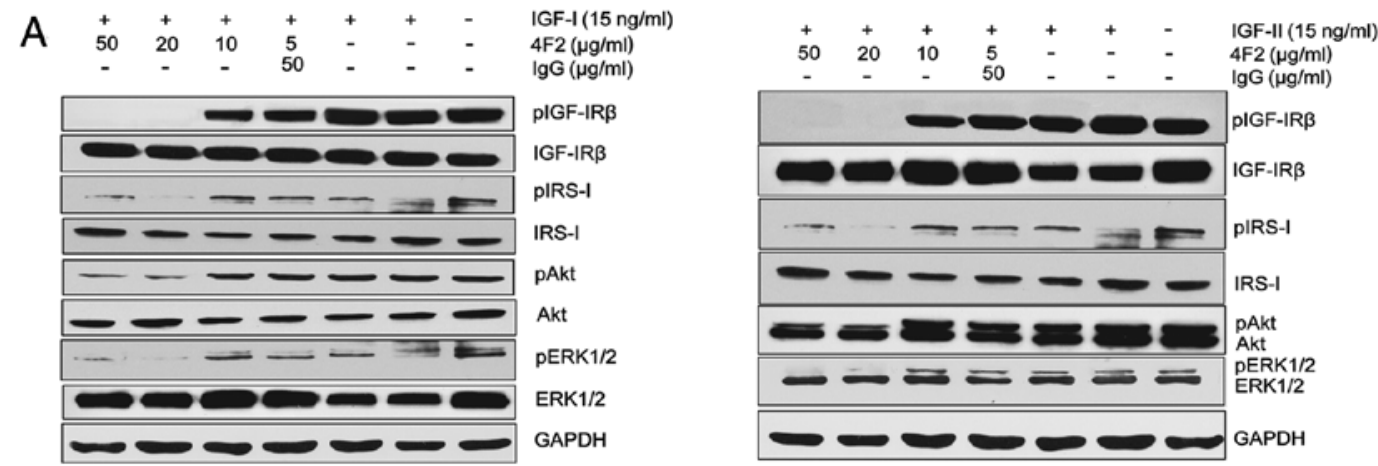

B
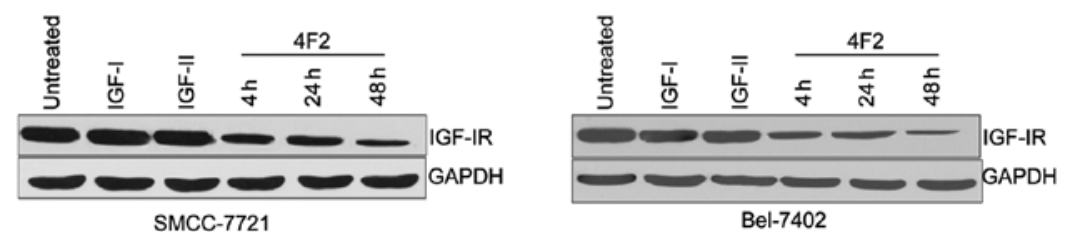

Figure 5. 4F2 inhibits IGF-IR signaling and downregulates expression of IGF-IR. (A) Dose-dependent inhibition of IGF-I-induced and IGF-II-induced IGF-IR $\beta$, IRS-1, AKT and ERK autophosphorylation with 4F2 treatment as described in materials and methods. (B) IGF-IR levels in SMMC-7721 and Bel-402 cells treated with $4 \mathrm{~F} 2$ for $4-48 \mathrm{~h}$ (or IGF-I/II for $48 \mathrm{~h}$ ) were analyzed by western blotting using an anti-IGF-IR $\beta$ chain c-20 antibody.

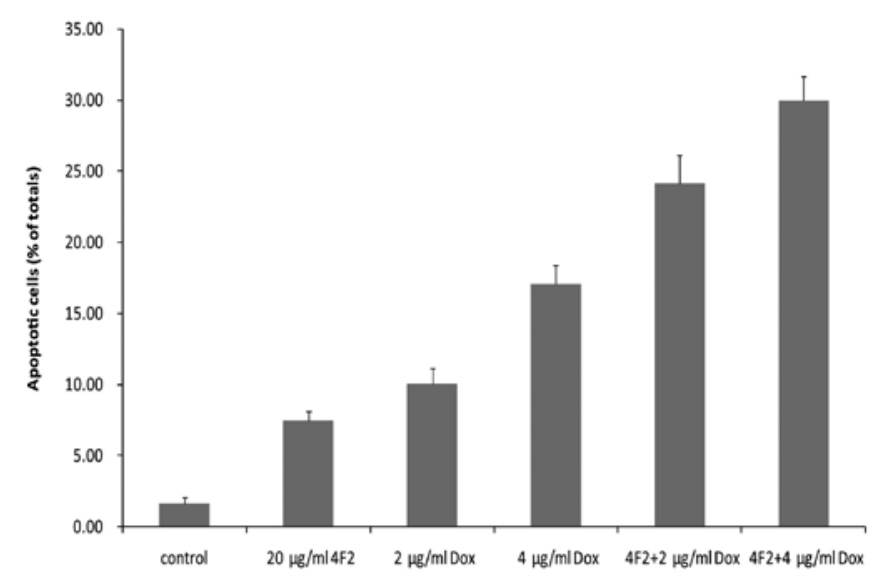

Figure 6. Effects of 4F2 and doxorubicin (Dox) on apoptosis of SMMC-7721 cell lines. Subconfluent cells were treated with 4F2 $(20 \mu \mathrm{g} / \mathrm{ml})$ and doxorubicin $(2-4 \mu \mathrm{g} / \mathrm{ml})$ alone or combination for $48 \mathrm{~h}$, and then apoptosis was analyzed by flow cytometry by Annexin V/propidium iodide detection. Mean (columns) $\pm \mathrm{SE}$ (bars). ${ }^{*} \mathrm{P}<0.05,{ }^{* *} \mathrm{P}<0.01$, statistically significant in comparison with control. in additivity of the rates of apoptosis induced by each single drug at the concentrations and time point tested.

$4 F 2$ regulates expression of apoptosis-specific and cell cycle regulating proteins. To elucidate the signaling pathways modulated by 4F2 inhibition in HCC cells, we investigated changes in the expression of apoptosis-specific proteins and cell cycle regulating proteins. Cells were incubated with IGF-I/II in the presence or absence of 4F2 for $48 \mathrm{~h}$. 4F2 dose-dependently downregulated anti-apoptotic Bcl-2 expression while upregulated pro-apoptotic Bax expression. Moreover, 4F2 downregulated cyclin D1 expression while upregulated p27 expression (Fig. 7).

\section{Discussion}

Several reports indicate that IGF-IRs are expressed frequently in HCC (32), most likely leading to the aggressive growth characteristics of tumors. Consequently, the IGF-IR is a prom-
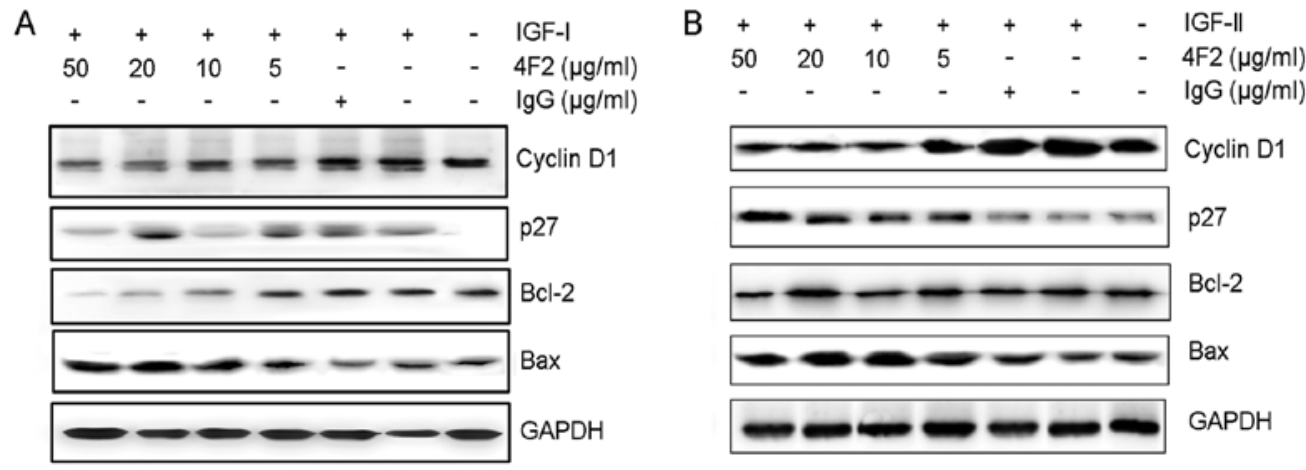

Figure 7. Effects of 4F2 on the expression of apoptosis-relevant proteins Bax, Bcl-2 and the cell cycle regulators. SMMC-7721 cells were grown to 50-60\% confluence and switched to serum-free medium. In 24 h, 4F2 was added and the cells were pretreated for $2 \mathrm{~h}$. (A) IGF-I or (B) IGF-II (20 ng/ml) was added and the cells were incubated for $48 \mathrm{~h}$. The cells were harvested and immunoblotting was performed. 
ising target for innovative treatment strategies in HCC. In the present study, we have generated a murine anti-IGF-1R antibody 4F2 which specifically recognizes IGF-IR but not insulin receptor. This selectivity may be an advantage over potential IGF-IR kinase inhibitors which may partly inhibit insulin receptor and induce hyperglycemia. By blocking IGF-IR activation, 4F2 can effectively inhibit its signal transduction. The relative contribution of these effects to the anticancer activity of 4F2 in different settings (including in vivo models) remains to be determined. To elucidate the underlying mechanisms of the 4F2 antiproliferative activity on HCC cells, the expression of apopotosis and cell cycle related proteins were also examined. Compared with untreated cells, 4F2 dose-dependently downregulated anti-apoptotic Bcl-2, pro-apoptotic Bax was upregulated. Moreover, cell cycle promoting cyclin D1 was downregulated, while the cell cycle arresting p27 was upregulated by $4 \mathrm{~F} 2$.

Since IGF-IR signaling has been shown to prevent tumor cells from the cytotoxic effects of chemotherapy and may play an important role in tumor cell drug resistance (33-35), we supposed that anti-IGF-IR antibody 4F2 may be combined with chemical drug for treating HCC. We then studied whether inhibition of IGF signaling alters chemosensitivity, the results showed that combined treatments using 4F2 with conventional cytotoxic agent doxorubicin, significantly increase the cytotoxic effects, suggesting that this combination might offer an alternative strategy for treating HCC. As we all known, chemotherapeutic drugs inhibit cancer cell growth mainly by inducing cell apoptosis. We also know that activated IGF-IR is a powerful inhibitor of apoptosis $(36,37)$. For instance, Dunn et al (38) reported that IGF-I could induce a $20-40 \%$ increase in cell survival of breast cancer cells treated with anticancer drugs. A study have proved that when the novel IGF-1R tyrosine kinase inhibitor NVP-AEW541 was combined with cytotoxic chemotherapy, additive antiproliferative effects were observed in HCC, Furthermore, combinatorial treatment with IGF-1R tyrosine kinase inhibitor NVP-AEW541 and cytotoxic drugs impose additive antiproliferative effects on HCC. However, the development of specific small molecule inhibitors of IGF-IR tyrosine kinase activity was challenging because of high degree of homology to insulin receptor. Because of the high specificity of 4F2 in recognizing IGF-1R, we think it may be a new substitute of TKI in combination with chemotherapeutic drug for treating $\mathrm{HCC}$. We observed that 4F2 actually sensitizes SMMC-7721 cell lines to doxorubicin, mainly by inducing apoptosis as shown in Fig. 6.

IGF-IR is a promising anticancer therapy target because of its defined role in establishing and maintaining the cancer phenotype. Our study provides first evidence that the growth of human hepatocellular SMMC-7721 cells can be potently suppressed by IGF-IR inhibition with anti-IGF-1R antibodies. Evidence suggesting a link between IGF-IR signaling and resistance to cytotoxic therapies provides rationale for combining IGF-IR inhibitors with chemotherapy. The present study is the first published report showing a favorable interaction between chemotherapy and IGF-IR blockade with an anti-IGF-IR monoclonal antibody. Anti-IGF-IR antibodies are therefore promising agents as monotherapy or in combination therapy for HCC.

\section{Acknowledgements}

This study is supported by the grant of Shandong Tackle Key Problems in Science and Technology (2010GSF10245); Shandong Excellent Young Scientist Research Award Fund Project (BS2010YY013).

\section{References}

1. Baserga R, Peruzzi F and Reiss K: The IGF-1 receptor in cancer biology. Int J Cancer 107: 873-877, 2003.

2. Pollak M: The insulin and insulin-like growth factor receptor family in neoplasia: an update. Nat Rev Cancer 12: 159-169, 2012.

3. Kaiser U, Schardt C, Brandscheidt D, Wollmer E and Havemann K: Expression of insulin-like growth factor receptors I and II in normal human lung and in lung cancer. J Cancer Res Clin Oncol 119: 665-668, 1993.

4. Parker AS, Cheville JC, Janney CA and Cerhan JR: High expression levels of insulin-like growth factor-I receptor predict poor survival among women with clear-cell renal cell carcinomas. Hum Pathol 33: 801-805, 2002.

5. Pekonen F, Nyman T, Ilvesmaki V and Partanen S: Insulin-like growth factor binding proteins in human breast cancer tissue. Cancer Res 52: 5204-5207, 1992

6. Resnik JL, Reichart DB, Huey K, Webster NJ and Seely BL: Elevated insulin-like growth factor I receptor autophosphorylation and kinase activity in human breast cancer. Cancer Res 58: 1159-1164, 1998.

7. Steller MA, Delgado CH, Bartels CJ, Woodworth CD and Zou Z: Overexpression of the insulin-like growth factor-1 receptor and autocrine stimulation in human cervical cancer cells. Cancer Res 56: 1761-1765, 1996.

8. Werner H, Re GG, Drummond IA, et al: Increased expression of the insulin-like growth factor I receptor gene, IGFIR, in Wilms tumor is correlated with modulation of $I G F I R$ promoter activity by the WT1 Wilms tumor gene product. Proc Natl Acad Sci USA 90: 5828-5832, 1993.

9. Breuhahn K and Schirmacher P: Reactivation of the insulin-like growth factor-II signaling pathway in human hepatocellular carcinoma. World J Gastroenterol 14: 1690-1698, 2008.

10. Chan JM, Stampfer MJ, Giovannucci E, et al: Plasma insulinlike growth factor-I and prostate cancer risk: a prospective study. Science 279: 563-566, 1998.

11. Vadgama JV, Wu Y, Datta G, Khan H and Chillar R: Plasma insulin-like growth factor-I and serum IGF-binding protein 3 can be associated with the progression of breast cancer, and predict the risk of recurrence and the probability of survival in AfricanAmerican and Hispanic women. Oncology 57: 330-340, 1999.

12. Boulle N, Logie A, Gicquel C, Perin L and Le Bouc Y: Increased levels of insulin-like growth factor II (IGF-II) and IGF-binding protein-2 are associated with malignancy in sporadic adrenocortical tumors. J Clin Endocrinol Metab 83: 1713-1720, 1998.

13. Martin DM, Singleton JR, Meghani MA and Feldman EL: IGF receptor function and regulation in autocrine human neuroblastoma cell growth. Regul Pept 48: 225-232, 1993.

14. Reeve AE, Eccles MR, Wilkins RJ, Bell GI and Millow LJ: Expression of insulin-like growth factor-II transcripts in Wilms tumour. Nature 317: 258-260, 1985.

15. Sohda T, Iwata K, Soejima H, Kamimura S, Shijo H and Yun K: In situ detection of insulin-like growth factor II (IGF2) and H19 gene expression in hepatocellular carcinoma. J Hum Genet 43: 49-53, 1998.

16. Takeda S, Kondo M, Kumada T, et al: Allelic-expression imbalance of the insulin-like growth factor 2 gene in hepatocellular carcinoma and underlying disease. Oncogene 12: 1589-1592, 1996.

17. Zhang L, Zhou W, Velculescu VE, et al: Gene expression profiles in normal and cancer cells. Science 276: 1268-1272, 1997.

18. Breuhahn K, Longerich T and Schirmacher P: Dysregulation of growth factor signaling in human hepatocellular carcinoma. Oncogene 25: 3787-3800, 2006.

19. Wilkin F, Gagne N, Paquette J, Oligny LL and Deal C: Pediatric adrenocortical tumors: molecular events leading to insulin-like growth factor II gene overexpression. J Clin Endocrinol Metab 85: 2048-2056, 2000. 
20. Denley A, Brierley GV, Carroll JM, et al: Differential activation of insulin receptor isoforms by insulin-like growth factors is determined by the C domain. Endocrinology 147: 1029-1036, 2006.

21. Adams TE, Epa VC, Garrett TP and Ward CW: Structure and function of the type 1 insulin-like growth factor receptor. Cell Mol Life Sci 57: 1050-1093, 2000

22. Perer ES, Madan AK, Shurin A, et al: Insulin-like growth factor I receptor antagonism augments response to chemoradiation therapy in colon cancer cells. J Surg Res 94: 1-5, 2000.

23. Burtrum D, Zhu Z, Lu D, et al: A fully human monoclonal antibody to the insulin-like growth factor I receptor blocks ligand-dependent signaling and inhibits human tumor growth in vivo. Cancer Res 63: 8912-8921, 2003.

24. Heron-Milhavet L, Karas M, Goldsmith CM, Baum BJ and LeRoith D: Insulin-like growth factor-I (IGF-I) receptor activation rescues UV-damaged cells through a p38 signaling pathway. Potential role of the IGF-I receptor in DNA repair. J Biol Chem 276: 18185-18192, 2001.

25. Kulik G, Klippel A and Weber MJ: Antiapoptotic signalling by the insulin-like growth factor I receptor, phosphatidylinositol 3-kinase, and Akt. Mol Cell Biol 17: 1595-1606, 1997.

26. Jacobs S, Cook S, Svoboda ME and van Wyk JJ: Interaction of the monoclonal antibodies $\alpha$ IR-1 and $\alpha$ IR-3 with insulin and somatomedin-C receptors. Endocrinology 118: 223-226, 1986.

27. Sachdev D, Li SL, Hartell JS, Fujita-Yamaguchi Y, Miller JS and Yee D: A chimeric humanized single-chain antibody against the type I insulin-like growth factor (IGF) receptor renders breast cancer cells refractory to the mitogenic effects of IGF-I. Cancer Res 63: 627-635, 2003.

28. Cohen BD, Baker DA, Soderstrom C, et al: Combination therapy enhances the inhibition of tumor growth with the fully human anti-type 1 insulin-like growth factor receptor monoclonal antibody CP-751,871. Clin Cancer Res 11: 2063-2073, 2005.

29. Lu D, Zhang $\mathrm{H}$, Koo $\mathrm{H}$, et al: A fully human recombinant IgG-like bispecific antibody to both the epidermal growth factor receptor and the insulin-like growth factor receptor for enhanced antitumor activity. J Biol Chem 280: 19665-19672, 2005.
30. Langone JJ: Applications of immobilized protein A in immunochemical techniques. J Immunol Methods 55: 277-296, 1982.

31. Pandini G, Vigneri R, Costantino A, et al: Insulin and insulin-like growth factor-I (IGF-I) receptor overexpression in breast cancers leads to insulin/IGF-I hybrid receptor overexpression: evidence for a second mechanism of IGF-I signaling. Clin Cancer Res 5: 1935-1944, 1999.

32. Scharf JG and Braulke T: The role of the IGF axis in hepatocarcinogenesis. Horm Metab Res 35: 685-693, 2003.

33. Benini S, Manara MC, Baldini N, et al: Inhibition of insulinlike growth factor I receptor increases the antitumor activity of doxorubicin and vincristine against Ewing's sarcoma cells. Clin Cancer Res 7: 1790-1797, 2001.

34. Gooch JL, Tang Y, Ricono JM and Abboud HE: Insulin-like growth factor-I induces renal cell hypertrophy via a calcineurindependent mechanism. J Biol Chem 276: 42492-42500, 2001.

35. Turner BC, Haffty BG, Narayanan L, et al: Insulin-like growth factor-I receptor overexpression mediates cellular radioresistance and local breast cancer recurrence after lumpectomy and radiation. Cancer Res 57: 3079-3083, 1997.

36. Nakamura S, Watanabe H, Miura $M$ and Sasaki T: Effect of the insulin-like growth factor I receptor on ionizing radiationinduced cell death in mouse embryo fibroblasts. Exp Cell Res 235: 287-294, 1997.

37. Sell C, Baserga R and Rubin R: Insulin-like growth factor I (IGF-I) and the IGF-I receptor prevent etoposide-induced apoptosis. Cancer Res 55: 303-306, 1995.

38. Dunn SE, Hardman RA, Kari FW and Barrett JC: Insulin-like growth factor 1 (IGF-1) alters drug sensitivity of HBL100 human breast cancer cells by inhibition of apoptosis induced by diverse anticancer drugs. Cancer Res 57: 2687-2693, 1997. 